\title{
Mariá Corbi, Rubem Alves e Carlos Dominguez Morano: três formas de pensar sobre Deus na hipermodernidade e a fé advinda da confluência dessas visões
}

\author{
Mariá Corbi, Rubem Alves and Carlos Dominguez \\ Morano: three ways of thinking about God in \\ hypermodernity and faith coming from the \\ confluence of these visions
}

\section{Mariá Corbi, Rubem Alves y Carlos Dominguez Morano: tres formas de pensar acerca de Dios en la hipermodernidad y la fe que surge de la confluencia de esas visiones}

Fabiano Veliq*

\begin{abstract}
RESUMO
O presente artigo reflete sobre a questão de Deus na hipermodernidade a partir de três autores contemporâneos, a saber, Mariá Corbi, Rubem Alves, e Carlos Dominguez Morano visando mostrar como que o conceito de Deus se manifesta em cada um desses autores e como que essa nova forma de pensar a questão sobre Deus interfere na forma como compreendemos a fé na hipermodernidade que se colocará não mais como uma adesão fixa a um discurso, mas como uma aposta de cunho existencial para o sujeito.
\end{abstract}

Palavras-chave: Deus; fé; aposta; sujeito.

\begin{abstract}
This article reflects about the question of God in hypermodernity from trhree contemporany authors; Mariá Corbi, Rubem Alves, and Carlos Dominguez Morano aiming to show how the concept of God manifests itself in each one of thes authors and how this new form of thinking the question about God interfers in the form we understand the faith in hypermodernity which will put itself not as an fixed adhesion to a discourse, but as an existencial bet. Keywords: God; faith; bet; subject.

RESUMEN

En este artículo se reflexiona sobre la cuestión de Dios en hipermodernidad de tres autores contemporáneos, a saber, Mariá Corbi, Rubem Alves y Carlos Dominguez Morano fin de mostrar cómo el concepto de Dios se manifiesta en cada uno de estos autores y la forma
\end{abstract}

* Graduado em Filosofia pela UFMG, especialista em Teologia Sistemática pela Faculdade Batista de Belo Horizonte, mestre em Filosofia da Religião pela FAJE, doutor em Psicologia pela PUC-MG, onde realizou estágio pós-doutoral em Psicanálise. 
en que se nueva forma de pensar acerca de la cuestión de Dios interfiere con la forma de entender la fe en hipermodernidad que no pone como una adhesión fija a un discurso, sino como una apuesta de la naturaleza existencial para el sujeto.

Palabras clave: Dios; fe; apuesta; sujeto.

\section{Introdução}

Tratar sobre a questão de Deus é sempre um problema muito grande, primeiramente por ser uma questão muito ampla e abordada por diversas áreas, tais como a Teologia, a Filosofia, a Antropologia etc. Depois, por ser uma questão que mobiliza muito as emoções, por ser um tema muito basilar em nossa relação com o mundo.

Por mais que o indivíduo queira estar alheio à questão de Deus, de uma forma ou de outra ele é sempre confrontado a dar alguma resposta em relação à sua crença - ou não - na existência de Deus. Assim, o mundo secularizado abre novas alternativas ao sujeito que não precisa acreditar em Deus para continuar vivendo ou fazendo suas tarefas. No entanto, percebemos que, mesmo diante dessas novas alternativas, a questão de Deus sempre aparece como uma forte alternativa.

Mas, o que aqui estamos chamando de Deus? É preciso que reduzamos o escopo do alcance deste termo para que fique claro o que temos em mente quando usamos esta palavra. Temos consciência de que é impossível circunscrever todas as concepções que foram dadas a esse termo no decorrer da história, e não é nossa pretensão fazer um levantamento de todas essas definições. No entanto, é interessante atentar para algumas mudanças sobre a concepção de Deus. Para isso, passamos a explicitar três propostas sobre Deus em autores contemporâneos.

\section{Um Deus que regressa como Silêncio - A proposta de Mariá Corbi}

A filosofia moderna, a partir de Descartes, caracteriza-se por uma tentativa de fundamentar toda a realidade no ser humano, de forma que Deus assume um papel fundamental para garantir a própria existência do sujeito pensante (DESCARTES, 1999). No entanto, apesar de toda a centralidade da questão de Deus no pensamento moderno, logo se verá que tal questão vai criando um caráter extremamente negativo, como podemos notar na obra de Feuerbach (FEUERBACH, 2002), em que impera um ateísmo bastante incisivo e, posteriormente, na obra de Sartre, que demonstra também um ateísmo muito forte.

No entanto, atualmente, a questão de Deus voltou a interessar a filosofia e a própria psicologia, e podemos colocar como possível causa deste 
"retorno" aquele esvaziamento das ideologias a que aludimos mais acima. Isso coloca a nossa tese dentro de um debate bastante atual.

É bastante claro, para nós, que a visão que se tem de Deus é condicionada socialmente. Aqui, a obra de Mariá Corbi pode ser de extremo auxílio para pensarmos essa construção do conceito de Deus. Corbi tenta mostrar que a ação central de um determinado grupo - no caso dos caçadores-coletores seria a caça e a colheita; no caso dos horticultores, a plantação etc. - gerará a metáfora central que se constituirá como nível profundo de sua construção mítica. Dessa forma, o conceito de Deus estaria sempre atrelado ao modo de vida de um determinado povo. Segundo Corbi,

os mitos moldam a realidade de acordo com certas formas determinadas de sobreviver no meio; eles a configuram, a delimitam, a objetivam segundo um sistema concreto de satisfazer necessidades [...] Fica evidente que os mitos e as narrações sagradas são só sistemas de figuração da realidade, de modelação de acordo com certas necessidades; eles são sistemas de representação, de objetivação, que orientam e dão eficácia à ação, de forma que os grupos possam sobreviver em condições de vida determinadas (CORBI, 2010, p. 123).

Dessa forma, percebe-se que, para Corbi, os mitos visam sempre dar uma resposta para uma necessidade determinada socialmente. Em sua análise posterior, Corbi tentará mostrar que, com o advento da era da tecnologia, os mitos perderam o seu caráter organizador do mundo, de forma que a era da tecnologia marca o início de um mundo sem crenças ou religiões ${ }^{1}$, no qual o contato do ser humano com o real absoluto seria entendido por um viés místico. ${ }^{2}$

A mística é vista por Corbi como sendo o futuro de uma vivência religiosa que não estaria mais atrelada à sua dimensão dogmática ou institucional, mas teria o seu foco na relação do homem com o mistério do mundo.

Religião aqui entendida como "um conjunto de narrações sagradas, de símbolos, mitos e rituais que geram e suportam um sistema de crenças - sistema que tem como resultado um projeto de vida coletiva e individual, e que, ao mesmo tempo, é um sistema de representação e de iniciação à dimensão absoluta da existência. Todo esse conjunto é tido como revelado por Deus, sendo, portanto, intocável e inalterável" (CORBI, 2010, p. 18).

2 Aqui, cabe ressaltar uma diferença entre o viés místico da Religião e o caráter individualizante tratado por nós no terceiro capítulo deste trabalho. Enquanto o caráter individualizante de algumas práticas religiosas dos nossos dias tem como consequência um fechamento autístico do sujeito sobre si, o viés místico tem sempre a preocupação de lançar de volta o sujeito no mundo de forma que ele faça a diferença onde está. A experiência mística tem sempre esse caráter transformador, tanto para o sujeito quanto para o seu meio. Ao invés de fechar o sujeito sobre si, a experiência mística se caracteriza por uma abertura do sujeito tanto ao transcendente quanto ao próximo. Para uma análise pormenorizada, cf. BETTO, Frei \& BOFF, Leonardo. Mistica e espiritualidade. Rio de Janeiro: Garamond, 2005. 
Segundo Corbi,

Podemos concluir afirmando que o caminho interior, o caminho espiritual, é possível sem submissão a mitos, a símbolos, a crenças, a sacralidades e a religiões. São, pois, possíveis a vida espiritual e a mística em uma sociedade completamente leiga e sem crenças (CORBI, 2010, p. 263).

Dessa maneira, a espiritualidade, chamada por ele de uma espiritualidade Leiga (p. 255), deverá ser vivida no interior da completa autonomia do sujeito, e não mais vinculada a qualquer tipo de discurso que seja normativo. Dens, aqui, apareceria como símbolo de um absoluto que seria experimentado pelo sujeito em forma de "silêncio". Este silêncio nos incita a conhecê-lo e a nos submergir nele. Tal conhecimento silencioso seria inefável e não pode ser atingido por nenhum método de conhecimento racional, mas é mero dom, é presença absoluta, presença da realidade absoluta que é, ao mesmo tempo, presença de nada e ninguém.

Essa forma de pensar o conceito de Deus como símbolo dessa dimensão absoluta inefável é bastante recorrente, principalmente na literatura oriental. Os livros do Baghavat Gita, os Vedas e outros livros sagrados orientais apontam nessa direção, e Corbi, obviamente, está bebendo dessa fonte ao propor tal "espiritualidade Leiga".

Outra forma possível de abordarmos esse conceito de Deus é a partir da noção de "sentido para a existência" e, aqui, o pensamento de Rubem Alves pode ser de grande valia para nós.

\section{Um Deus que retorna como Esperança - a proposta de Rubem Alves}

Para Rubem Alves, teólogo e filósofo brasileiro, em nosso tipo de sociedade não há lugar para o Deus metafísico. Este Deus, enquanto "entidade metafísica", foi abandonado no discurso moderno. Para Alves, o existencialismo criou um novo lugar para Deus, mas Ele não é o mesmo ${ }^{3}$. Com efeito, nos pensadores existencialistas teístas, como Kierkegaard, Deus deixa de ser uma entidade metafísica e passa a ser uma exigência da interioridade humana. A linguagem sobre Deus não aponta mais para um "objeto" que estaria lá fora, mas sim para o próprio homem. O mesmo homem que, antes, tenta dar

\footnotetext{
Temos consciência de que esse novo lugar para Deus, de que Rubem Alves trata, não é criado pelo existencialismo, mas advém do desenvolver da filosofia ocidental. Nesse sentido, o belíssimo texto de Pe. Vaz, intitulado O problema de Deus no pensamento contemporâneo, nos dá uma exposição densa e concisa desse desenvolvimento da filosofia ocidental sobre a questão de Deus. Cf. LIMA VAZ, H.C. de. O problema de Deus no pensamento contemporâneo. Síntese Nova Fase, Belo Horizonte, v. VIII, n. 23, set./dez. 1981.
} 
sentido à vida através da ciência, constata que ela não é capaz de responder a seus anseios. A experiência do absurdo se instaura e, sobre esse assunto, o discurso científico não pode falar. A "morte de Deus"4 envolve a impossibilidade de falar. Depois da "morte de Deus", Ele passa a ser símbolo da relação Eu-Mundo. Ou seja, segundo Vattimo, "sob a luz da nossa experiência pós-moderna, isto significa que, justamente porque este Deus-fundamento último, que é a estrutura metafísica do real, não é mais sustentável, torna-se novamente possível uma crença em Deus" (VATTIMO, 2004, p. 12).

Nas palavras de Alves, "Deus nasce como expressão de uma relação. [...] A palavra Deus não se refere nem ao Eu e nem ao Mundo, mas antes ao hífen, à relação invisível que os une" (ALVES, 2007, p. 65).

A situação do homem diante de Deus passa a ser descrita de forma paradoxal: a ausência de Deus é a única forma de sua presença (ALVES, 2007, p. 80), crer em Deus é viver como se Ele não existisse - no entanto, a coragem está em afirmar o sentido apesar de. Essa coragem silenciosa emerge das profundezas obscuras do ser, não deriva da fé em Deus, mas persiste, apesar da "morte de Deus". Essa coragem é a fé absoluta. Fé que não se relaciona a nenhum objeto. Deus desaparece enquanto objeto para se assumir enquanto esperança.

O Deus que se revela na hipermodernidade é um Deus que se revela pelo "ouvir falar" (Fides ex auditu) e, por isso, traz consigo toda a margem de incerteza que está ligada a todas as coisas que consideramos verdadeiras porque ouvimos de outras pessoas em quem confiamos, ou seja, está sempre condicionada por um respeito, por um amor a quem fala.

Deus, portanto, é visto como essa ânsia pela busca de um sentido para a existência. Deus se transforma em horizonte que o homem vislumbra. Diante do silêncio, da "morte de Deus", resta apenas a esperança. Como afirma Alves,

Deus desaparece como objeto. [...] Mas sua presença continua de forma mais estranha, porque ela se anuncia numa consciência de ausência, na saudade de um bem-amado que nos deixou ou que ainda não veio. E a consciência de Deus como objeto se transforma em esperança: não uma consciência de algo, mas no simples tender da consciência para um imenso vazio que a enche de nostalgia. Nas linhas de Ernst Bloch, temos, então, de afirmar que, onde quer que exista a esperança, ali existe a Religião, porque aí se revela a nossa nostalgia pelo Reino de Deus, o grande projeto utópico que a humanidade

4 A morte de Deus, para Nietzsche, não se configura uma afirmação de ateísmo, como se ele dissesse que Deus não existe. Segundo Vattimo, "uma tese do gênero, a não-existência de Deus, não poderia ter sido professada por Nietzsche, pois, do contrário, a pretensa verdade absoluta que esta encerraria ainda valeria para ele como um princípio metafísico, como uma 'estrutura' verdadeira do real que teria a mesma função do Deus da metafísica tradicional” (VATTIMO, 2004, p. 9). 
não cessa de sonhar mesmo quando, de olhos abertos, ela não tenha condições de ver. (ALVES, 2007 p. 82)

O homem que "mata Deus" sente a necessidade de colocar algo em seu lugar, e Deus retorna, passando agora a ser o símbolo da esperança ou, nas palavras de Alves,

Ora, o que é Deus? O símbolo da plausibilidade dos meus valores, a promessa da salvação, a realidade onipotente dos meus anseios, o poder da minha fraqueza. Deus é o símbolo da esperança: a esperança corporificada na imaginação. Destituída a esperança, morrem os deuses. Destituídos os deuses, morre a esperança (ALVES, 2007 p. 145).

Percebe-se que esse Deus não habita o lugar dos discursos, a fala sobre Deus está interditada. Resta o silêncio apenas, no máximo uma Teologia negativa. Mesmo assim, Ele assume outra forma, assume a forma da esperança, que fará com que a Religião deixe de ser um inventário de coisas celestes e passe a ser uma atitude em relação ao mundo, visando transformar as condições de existência. Deus, enquanto símbolo da esperança, é aquele que motiva o homem a ser de uma forma diferente diante do mundo. Não importa mais o que se fala sobre Deus, mas sim como se vive no mundo recebido como dádiva de Deus.

Percebe-se que falar sobre Deus é falar sobre os desejos desse homem. Por isso, todo discurso sobre Deus nada mais é que um discurso sobre o ser humano.

Percebe-se uma semelhança muito grande com Feuerbach nesse ponto. No entanto, há uma diferença entre o pensamento alvesiano e a proposta feuerbachiana.

Feuerbach concebe a Deus como objetivação humana ${ }^{5}$. Em suas preleções sobre a essência da Religião, esse autor tentou mostrar que Deus nada mais é que um ser imaginário, uma entidade da fantasia e, como a fantasia, é aquilo sobre o qual a poesia se baseia. Pode-se, assim, dizer: "a Religião é poesia, um Deus é um ser poético” (FEUERBACH, 1989 p.153).

Alves (2006) concorda com Feuerbach, quando este afirma que refletir sobre Deus é refletir sobre o homem e também quando apresenta Deus como ser poético. De acordo com Alves, Deus pode, sim, ser visto dessa forma, pois, na poesia, o que está em jogo também é a tentativa de exprimir o inexprimível. Se Deus é poesia e a poesia é expressão do desejo humano, Deus pode ser tomado como forma de realizar essa expressão. Em Alves, a

\footnotetext{
5 E sabemos como esse discurso de Feuerbach influenciou bastante o pensamento de Freud e vários outros sobre a questão religiosa.
} 
Religião também é poesia, embora revele algo humano: os desejos do coração humano, assim como a esperança do homem diante da vida. Encarar a Religião como poesia faz com que se evitem os dogmatismos, uma vez que sobre ela não recairá a pergunta sobre a verdade ou a falsidade. Falar sobre Deus é sempre fazer poesia, é expressar desejos de um mundo melhor para os indivíduos. Encarar Deus como poesia é encará-lo como expressão humana.

Dessa forma, Deus não é mais visto como um ser supremo, mas como horizonte a que todo indivíduo tende. Mas irá se associar de forma direta ao desejo de criar uma ordo amoris, um mundo que faça sentido.

A linguagem que quer falar sobre Deus falará sobre justiça social, sobre condições materiais dignas para os indivíduos, sobre a esperança de viver em um mundo que faça sentido. Não será uma linguagem capaz de abarcar o transcendental, mas será uma prática visando fazer com que o homem retorne ao Éden.

Nesse sentido, Alves, ao refletir sobre Deus, não se refere a um ser transcendente, mas a um ser que age na história do homem e que é expressão deste.

Como aponta Cervantes-Ortiz,

o deus da Religião não se entende nem se vive racionalmente; de fato, há tantos deuses, sem a possibilidade de se harmonizarem, quanto religiões; eles são "hipóteses vitais", "sintomas de uma imensa variedade de projetos de vida", motivo pelo qual se revela impossível dizer qual é o verdadeiro. O discurso religioso surge do corpo do ser humano, de cada homem/mulher, de sua unicidade absoluta (CERVANTES-ORTIZ, 2005, p. 152).

\section{Deus e a Psicanálise - a proposta de Carlos Dominguez Morano}

Segundo Morano (2006), para a Psicanálise, a noção de Deus ganha nome, forma e figura a partir da figura paterna que instaura o desejo. A palavra que humaniza o sujeito possibilita que a noção de Deus apareça, e várias vezes fará com que esta noção apareça de forma extremamente doentia. No entanto, Deus, como estamos pensando aqui, não precisa, necessariamente, se configurar em sua dimensão doentia, mas pode ser vivenciado como algo que mobilize o sujeito à sua realização.

Morano se expressa a respeito do diálogo entre a Psicanálise e a dimensão da fé. Uma vez que a Psicanálise assume um descentramento do sujeito em relação a si mesmo, colocando-o diretamente como "filho da terra",

o sujeito se vê, agora, como um filho da terra e se reconhece capaz de viver como tal; sabe, agora, realmente (e não como uma pura ideologia teológica da "morte de Deus") que poderia ser ateu. Não precisa de Deus, nem necessita rezar para viver. Não o necessita do mais profundo do seu ser. Nesses momentos, o nada e a descrença apa- 
recem como algo tão real como possível. Um nada que, por outro lado, não conduz, necessariamente (contra o que se tende a pensar), ao absurdo ou ao desalento diante da vida. Pelo contrário, pode mesmo oferecer a possibilidade do encontro consigo mesmo, com os outros e com o mundo. Um encontro autêntico, porque já não brota da necessidade, mas de um desejo que reconhece sua carência. A partir dela, emerge o outro como homem ou como mulher; surgem os companheiros de existência; surge o mundo como potencial de criação, de sentido e de projeto a realizar. Talvez Deus também possa surgir novamente, mas será de uma maneira distinta; o lugar do "totem" tornou-se vazio; o lugar do sonho, da ilusão e do somatório dos objetos totais ficou deserto. E, no vazio, apenas um desejo que remete à própria história e ao próprio futuro. Se Deus está, está de outro modo. E o sujeito sabe muito bem "por onde já não pode caminhar", por mais que a análise não lhe indique (nunca deverá fazê-lo) "para onde deverá dirigir seus passos" (MORANO, 2003, p. 106-107).

Essa nova forma de pensar o conceito de Deus nos afasta de sua forma mais comumente aceita pelo senso comum, e até mesmo de um Deus como pensado por Freud ${ }^{6}$, um Deus entendido como um ser onipotente, onisciente e onipresente. Esse Deus aparece agora como um Deus fragilizado, um Deus mais humanizado, como um Deus que, talvez, nem precise existir para que se acredite nele, um Deus que aparece como Outro a quem posso acessar a partir da figura de um próximo. ${ }^{7}$

Deus deixa de estar sempre ali, tão à mão e tão seguro, e, na experiência de oração, o sujeito pode até acreditar que Deus se encontra ali, mas não tem mais nenhuma certeza disso. Deus, quando visto dessa forma, escapa a todo tipo de verificação, e constitui-se, por mais real que seja, em uma "fantasia" do sujeito. Deus aparece no jogo do desejo sempre mediado pelos símbolos que são, via de regra, construídos socialmente. O Tu a quem endereça a sua oração acaba se encerrando em um "eu" que procura incessantemente algo para dar sentido à sua existência. Este caminho é o percorrido pelos grandes místicos. À medida que iam se aprofundando no caminho da oração, deram-se conta de que Deus não pode ser confundido com as mediações

${ }^{6}$ Podemos dizer que, em Freud, haveria várias figuras de Deus. Há o deus de Schreber, que exige dele coisas absurdas, há o deus do pequeno Hans, que aparece de forma mais ligada à noção de pai propriamente dita, e classicamente a visão de Deus atribuída por Freud nos textos em que trata da questão religiosa, ou seja, Deus visto quase sempre como uma projeção dos desejos humanos, na linha de Feuerbach, ou a noção de um pai idealizado, como atesta em $O$ mal-estar da civilização, O futuro de uma ilusão, e Moisés e o Monoteísmo.

7 Essa proposta, chamada por alguns de "pós-teísmo”, remete a pensar Deus fora da estrutura teísta, de um Deus que controlaria todas as coisas, como uma visão clássica cristã colocaria. Uma visão bem estruturada dessa proposta pode ser encontrada em John Shelby SPONG. Um novo cristianismo para um novo mundo. Campinas: Verus, 2006. Nessa obra, Spong tentará mostrar como a vinculação entre a figura de Jesus e uma visão teísta do mundo seria algo forjado pelos primeiros cristãos que, de alguma forma, distorceram as palavras de Jesus. 
humanas, de forma que, no final, restaria apenas um silêncio absoluto, um não-saber, o nada. ${ }^{8}$

No entanto, esse novo encontro com Deus, que não está preso à visão de um pai idealizado e nem de uma mãe "totalizadora", tem como destino o sair ao encontro do mundo, assumir a dureza da realidade e empenhar-se na transformação dela ${ }^{9}$. Não que agora esse Deus estaria desprovido de todo caráter afetivo; ele ainda pode ser vivenciado simbolicamente como pai ou mãe, com toda a carga afetiva que esses significantes carregam para o sujeito. No entanto, o sujeito que compreende Deus dentro dessa nova estrutura é capaz de entender o caráter simbólico da sua relação com esse a quem pode até chamar de Pai ou Mãe. Isso o traz sempre para a realidade que o envolve, assume a falta estrutural em seu centro, mas, nem por isso, esse Deus deixa de ser reverenciado pelo sujeito.

Situada nesse plano simbólico, a própria fé e a oração nos proporcionam a possibilidade de vivenciar os nossos valores de forma que a justificação última da nossa própria fé se daria sempre na profunda experiência que dela temos.

Esse Deus fraco é o que regressa na hipermodernidade. Não mais um Deus que pretende dizer o que é certo e o que é errado, mas um Deus visto como possível sentido para a existência.

O que temos aqui é uma inversão para a abordagem da questão: ao invés de se partir da ideia de Deus como absoluto transcendente para verificar se ela tem ou não consistência real, o que propomos é que se parta do ser humano em busca do fundamento último da sua existência, enquanto ser racional e livre, enquanto pergunta pelo sentido e, na resposta a esta pergunta, uma possível resposta sobre Deus.

8 O livro A noite escura (1960), de São João da Cruz, remete a essa dimensão de um encontro com Deus que se converte em um nada, um grande vazio que envolve o místico. Cf. DA CRUZ, São João. $A$ noite escura. In: Obras de São João da Cruz. Tradução das Carmelitas Descalças do Convento de Santa Teresa do Rio de Janeiro. Petrópolis: Vozes, 1960.

9 Uma referência interessante para pensar essa temática do ponto de vista da Teologia é o excelente livro de John Hick, intitulado A metáfora do Deus encarnado (2000), em que Hick propõe reler o dogma da encarnação de Jesus a partir dos próprios textos bíblicos para mostrar que Jesus, propriamente, nunca teria dito de si que seria Deus encarnado, mas esse dogma seria uma adaptação posterior dentro da história da Igreja. A partir dessa desconstrução, o autor tentará mostrar como seria possível um diálogo do cristianismo com outras formulações religiosas. Uma vez que Jesus não se configura como Deus encarnado, as outras experiências de fé seriam tão verdadeiras e válidas quanto àquelas propostas pelo cristianismo, de forma que as diversas religiões existentes no mundo seriam tentativas de dizer a experiência de um Real que transcenderia o ser humano. Essas tentativas de discurso sobre esse real poderiam assumir formas de um absoluto entendido pessoalmente (como o caso do cristianismo, islamismo, judaísmo) e de um absoluto entendido de forma impessoal (hinduísmo, budismo, taoísmo). Cf. HICK, John. A metáfora do Deus encarnado. Petrópolis: Editora Vozes, 2000. 


\section{A fé como aposta}

Se, como acabamos de ver, Deus se coloca como sentido possível para o sujeito hipermoderno, a fé nesse Deus também precisa ser repensada. Afirmamos, há pouco, que a fé que se propõe na hipermodernidade é uma fé que se baseia na confiança, no sentimento de amizade e de amor por quem transmite determinada palavra a nós. Se a fé realmente se coloca dessa maneira, ela fica extremamente condicionada à sua dimensão existencial, ou seja, coloca-se como uma grande aposta, extremamente arriscada. Esta fé, que se coloca como aposta, não tem absolutamente nada a ver com a aceitação de dogmas ou disciplinas impostas por autoridades eclesiásticas, mas com uma vivência do indivíduo que, por causa dela, coloca-se de forma diferente em relação ao mundo.

O termo fé (do latim fides, e do grego pistis) geralmente vem associado ao termo "crença", de forma que tais termos se mostram como sinônimos na língua portuguesa ${ }^{10}$. Tais termos carregam consigo uma grande carga religiosa e são, basicamente, usados apenas dentro do contexto religioso. No entanto, cabe ressaltar três possíveis empregos para o termo fé:

1 - Crer/fé como conhecimento, que implica um significado meramente cognitivo do termo, excluindo o seu caráter fiducial. O que se tem em mente nesse uso do termo é uma afirmação mais ou menos firme ou segura, e tem como uso corriqueiro os termos como "acho que", "penso que" etc. O uso se assemelha a uma espécie de opinião ou um parecer.

2 - Crer/fé como aceitação de um testemunho. E aqui teríamos basicamente dois tipos desse emprego do termo. O primeiro seria uma crença em um testemunho "funcional", e aqui estaria em questão a adesão do sujeito a um discurso que não se funda em uma evidência direta da coisa conhecida, mas na suposta evidência da verdade da afirmação do outro. A pessoa que dá o testemunho é mediadora entre o sujeito que acredita e aquilo em que ele acredita. Por exemplo: acredito que choveu em determinado lugar porque ouvi no rádio que choveu ali. Embora não conheça pessoalmente o radialista, acredito em sua fala, pois tenho razões suficientes para julgar que ele não está querendo enganar os ouvintes etc.

10 Por exemplo, na definição do dicionário online (http://www.dicio.com.br/crenca/), ou então na própria definição do Google, que define a crença como: "1. Estado, processo mental ou atitude de quem acredita em pessoa ou coisa ('Revela uma grande crença'); 2. Fé, em termos religiosos; 3. Convicção profunda ('Sua crença no partido não esmoreceu'); 4. Opinião manifesta com fé e grande segurança ('Nossa crença é de que venceremos'); 5. Aquilo ou aquele em que se crế; o objeto ou alvo de uma crença; 6. No pensamento medieval, fé religiosa, convicção na doutrina e nos ensinamentos sagrados, considerados compatíveis e coerentes com a reflexão racional; 7. No empirismo moderno, disposição subjetiva a considerar algo certo ou verdadeiro, por força do hábito ou das impressões sensíveis" (Disponível em https: / www.google.com.br/webhp? sourceid=chrome-instant\&ion=1\&espv=2\&ie=UTF$-8 \# \mathrm{q}=$ define $\% 3 \mathrm{~A} \% 20$ cren $\%$ C3\%A7a. Acesso em: 26/01/2015). 
Ainda outra forma de crença/fé no testemunho pessoal é o que acontece no campo da comunicação interpessoal. A aceitação do testemunho do outro não se funda em razões objetivas, mas na credibilidade própria da testemunha, isto é, no fato de ser aquela pessoa que atesta o que alguém aceita como verdadeiro. Creio porque confio em quem diz ${ }^{11}$. Este é o tipo de fé a que alude Vattimo em seu livro já citado por nós.

3 - Fé como confiança. O terceiro tipo é a crença/fé como confiança, e ela implica a dimensão da fé que está firmada em uma experiência pessoal do sujeito. Implica também, ao mesmo tempo, uma adesão do sujeito em uma relação de confiança para com Deus de forma a fiar a sua própria existência nesse tipo de crença. É uma adesão existencial, e não meramente cognitiva ou vinda de um testemunho alheio, mas o próprio fiel testemunha a respeito de em quem ele crê.

Podemos afirmar que a fé tem como mãe o desejo. Ou seja, sem o desejo do outro que nos acolhe, desde o nosso nascimento, não haveria a possibilidade da fé.

Morano define o crer deste modo:

Creer significa, entre otras cosas, poseer uma confianza básica en la vida. Contar con una certeza, no demonstrable, de que la vida y el mundo poseen un sentido, una lógica y una finalidad, por complicada que a veces nos resulte comprendela. [...] Creer significa, de un modo muy fundamental, poseer una certeza de que pase lo que pase, al final no nos hundiremos en un pozo sin fondo; sino que, finalmente, seremos sostenidos y protegidos $^{12}$ (MORANO, 2006, p. 201).

Esse sentimento de confiança, que Morano atribui à criança, advém, como sabemos, do fato de a criança ter sido primeiramente desejada pelos pais. A mãe, ao proporcionar o primeiro sentimento de felicidade e proteção ao filho, possibilita que a criança desenvolva o sentimento de um "abandono confiado", que mais tarde também estará intimamente ligado à dinâmica da fé.

11 A Teologia cristã, a partir de São Tomás de Aquino, propõe uma distinção entre credere Deum, credere Deo e credere in Deum. O credere Deum implica a crença que Deus existe. O credere Deo (creio a Deus) exprime uma confiança pessoal, uma noção de entrega a Deus, vendo nele a razão para aceitar sua Palavra, e o credere in Deum (creio em Deus) indica o bem e o fim para o qual oriento meu ser e minha vida. Para uma análise pormenorizada e com suporte histórico da discussão do uso desses termos, recomendo a leitura de JOSAPHAT, Frei Carlos. Crer no amor universal. Visão histórica, social e ecumênica do "Creio em Deus Pai" (2001) JOSAPHAT, Frei Carlos. Crer no amor universal. Visão histórica, social e ecumênica do "Creio em Deus Pai”. São Paulo: Loyola, 2001.

12 Tradução livre do autor: "Crer significa, entre outras coisas, possuir uma confiança básica na vida. Contar com uma certeza, não demonstrável, de que a vida e o mundo possuem um sentido, uma lógica e uma finalidade, por mais complicada que às vezes nos pareça compreendê-la [...] Crer significa, de modo muito fundamental, possuir uma certeza de que, aconteça o que acontecer, ao final não nos afundaremos em um poço sem fundo, mas sim que, finalmente, seremos sustentados e protegidos". 
Mas, da mesma forma que esse primeiro contato faz nascer o sentimento de um "abandono confiado", o desejo pode também sufocar a fé. Para que isso não aconteça, é preciso que o sujeito aceite a sua falta estrutural introduzida pela Lei da palavra que o humaniza, do contrário há sempre a possibilidade de querer confundir Deus com o seio imaginário da mãe.

Uma vez aceita essa separação, é possível acessar a relação com esse Outro sem visar apenas uma perda narcísica de si, ou apenas um retorno a uma instância totalizante. Obviamente, sempre há o risco da perda, tanto para o lado de uma totalização, quanto para o lado de uma fixação à palavra, à Lei, à exigência perfeccionista, ao ideal nunca alcançável caracterizado pelo viés mais dogmatista, fundamentalista e fanático. Nesse caso, a imagem de Deus é terrivelmente pervertida. Deus se torna o inimigo do desejo, inimigo da satisfação, inimigo da felicidade. Deus se torna o grande rival do prazer do sujeito, e o desejo é sufocado por um Deus extremamente rígido e cruel.

Outra forma de compreender a fé (pistis) é entendê-la como crédito. Segundo Agamben, (2012)13 "pistis", "fé, é simplesmente o crédito do qual gozamos junto de Deus e do qual a palavra de Deus goza junto de nós, a partir do momento em que acreditamos nela". Esta dimensão da fé, que é abordada por Paulo, quando afirma que "ora, a fé é o firme fundamento das coisas que se esperam, e a prova das coisas que se não veem” (Hb 11.1), é o que dá realidade àquilo que não existe ainda, mas em que acreditamos e confiamos; em que colocamos em jogo o nosso crédito e a nossa palavra. Algo como um futuro existe na medida em que a nossa fé consegue dar substância, isto é, realidade, às nossas esperanças. Se a fé é fundamento, como nos aponta Paulo, então ela "quer" que aquilo em que eu tenho fé seja realmente existente. Não é porque a coisa existe que eu acredito nela, mas o processo é inverso. A coisa existe porque eu tenho fé que ela existe.

A fé, dessa forma que estamos colocando aqui, conduz o homem a uma questão existencial. O homem está disposto a colocar sua vida inteira sobre esse fundamento. Isso, portanto, não é mero "acho que". A fé coloca a questão da vida e da morte em sua esteira. Por isso, ela não é qualquer fundamento, mas sim um "firme" fundamento. Ela não está pautada em um "achismo", mas está existencialmente arraigada no ser humano.

No entanto, tal fé nunca dá certeza de nada. Não há garantias, não há certezas. O que há é um indivíduo diante da morte, tentando dar sentido à sua vida, e, para dar esse sentido, é preciso que ele acredite, que fie toda sua

13 Trecho de um artigo publicado no jornal La República, em 16 fev. 2012, e traduzido no site do Instituto Unisinos. O artigo pode ser lido em: http://www.ihu.unisinos.br/noticias/506810-quando-a-religiao-do-dinheiro-devora-o-futuro-artigo-de-giorgio-agamben. Acesso em 08 de julho de 2017. 
existência em algo, que, segundo o texto, não pode ser visto. A fé é, portanto, o fundamento das coisas que não se veem. Ela é a base das coisas que se esperam, uma vez que somente pela fé esperamos algo que não vemos, e, por isso, é ela mesma a prova das coisas que não se veem. O que não é visto é "provado" pela fé que "cria" os objetos de sua crença. Como citado acima, não é porque a coisa existe que se acredita nela, mas é porque eu acredito nela que é possível que a fé seja o "firme fundamento" das coisas que se esperam e a prova das coisas que não se veem. Kierkegaard ilustra essa fé na figura do "cavaleiro da fé", que está disposto a dar o "salto no escuro", sempre confiante de que alguém ou algo o acolherá, mas sempre sem nenhuma certeza (KIERKEGAARD, 1964).

Esse tipo de fé só é possível se está baseada em uma experiência pessoal do sujeito; o sujeito precisa daquele terceiro tipo de crença/fé que explicitamos mais acima, ou seja, ele crê porque ele mesmo foi testemunha, porque ele confia naquilo que testemunhou e, por isso, está disposto a se entregar.

\section{Conclusão}

Nosso artigo pretendeu explicitar algumas formas contemporâneas de compreensão a respeito de Deus. Para isso, utilizamos como referências os pensamentos de Mariá Corbi, Rubem Alves e Carlos Dominguez Morano, no intuito de lançar luz sobre esta questão que se mostra fundamental em nossos dias. A partir desta nova visão sobre Deus, propomos uma compreensão da fé como uma aposta existencial do sujeito na tentativa de encontrar um sentido para a sua existência, não mais vinculada apenas à adesão a algum tipo de discurso, mas como confiança em Deus que pressupõe a entrega do sujeito, uma vez que ele testemunha por si mesmo a credibilidade daquele a quem se entrega.

Os conceitos de Deus e fé, entendidos dessa forma, proporcionam nova forma de pensar a religião na hipermodernidade. Tal religião não se caracterizará pela adesão fixa a um discurso, mas se voltará para a dimensão existencial do sujeito que, para além de se fechar em si mesmo, promoverá uma abertura em direção ao Outro, propiciando a vivência em uma comunidade.

\section{Referências bibliográficas}

AGAMBEN, Giogio. Quando a religião do dinheiro devora o fututo. Tradução de Moisés Sbardelotto. São Leopoldo: Instituto Humanitas Unisinos, 2012. Disponível em http://www. ihu.unisinos.br/noticias/506810-quando-a-religiao-do-dinheiro-devora-o-futuro-artigo-de-giorgio-agamben. Último acesso em 08 de julho de 2017.

ALVES, Rubem. O enigma da Religião. 6 ed. Campinas: Papirus, 2007. 175 p.

ALVES, Rubem. O suspiro dos oprimidos. 6. ed. São Paulo: Paulus, 2006. 180 p. 
BETTO, Frei \& BOFF, Leonardo. Mística e espiritualidade. Rio de Janeiro: Garamond, 2005. 213 p. BÍBLIA SAGRADA. Tradução King James. Disponível em: https://www.bibliaonline.com. br/kjv. Acesso em: 29 dez. 2014.

CERVANTES-ORTIZ, Leopoldo. A Teologia de Rubem Alves: poesia, brincadeira e erotismo. Campinas: Papirus, 2005. 250 p.

CORBI, Mariá. Para uma espiritualidade Leiga. Sem crenças, sem religiões, sem deuses. Tradução de Maria Stela Gonçalves. São Paulo: Paulus, 2010. Coleção Tempo Axial.

DA CRUZ, São João. A noite escura. In: Obras de São João da Cruz. Tradução das Carmelitas Descalças do Convento de Santa Teresa do Rio de Janeiro. Petrópolis: Vozes, 1960. 2 vols.

DESCARTES, René. Meditações sobre filosofia primeira. São Paulo: Cemodecon, 1999. 225 p.

FEUERBACH, Ludwig. Preleções sobre a essência da Religião. 2. ed. Campinas: Papirus, 1989. $296 \mathrm{p}$.

HICK, John. A metáfora do Deus encarnado. Petrópolis: Vozes, 2000. 230 p.

JOSAPHAT, Frei Carlos. Crer no amor universal. Visão histórica, social e ecumênica do “Creio em Deus Pai”. São Paulo: Loyola, 2001.

KIERKEGAARD, Soren. Temor e Tremor. São Paulo: Exposição do Livro, 1964. 115 p.

LIMA VAZ, H.C. de. O problema de Deus no pensamento contemporâneo. Síntese Nova Fase, Belo Horizonte, v. VIII, n. 23, set./dez. 1981.

MORANO, Carlos Dominguez. Crer depois de Freud. Tradução de Eduardo Dias Gontijo. São Paulo: Loyola, 2003. 342 p.

MORANO, Carlos Dominguez. Experiencia Cristiana y psicoanálisis. Maliaño: Editorial Sal Terrae, 2006. 255 p.

VATTIMO, Gianni. Depois da cristandade. Tradução de Cynthia Marques. Rio de Janeiro: Record, 2004. 173 p.

Submetido em: 24-4-2017

Aceito em: 21-6-2017 